\title{
EDUCAÇÃO AMBIENTAL COMO INSTRUMENTO PARA O DESENVOLVIMENTO LOCAL: UMA ANÁLISE TEÓRICA
}

Eliton Janio Araújo Ferreira ${ }^{1}$

Marilena Loureiro da Silva ${ }^{2}$

Resumo: O presente trabalho objetiva apresentar a Educação Ambiental como instrumento para o desenvolvimento local. Como forma de embasar essa formulação analisou-se o conceito de desenvolvimento local a partir da análise de diversos autores, relacionando-os com os pressupostos da Educação Ambiental. A metodologia para a realização deste estudo concentrou-se em uma pesquisa bibliográfica por meio de diversos instrumentos, dentre eles: livros, artigos publicados em periódicos, sites, dentre outros. Como resultados, verificou-se que a Educação Ambiental possui uma articulação com o conceito de desenvolvimento local, o que faz com que essa se constitua como um importante instrumento para a promoção desse desenvolvimento.

Palavras-chave: Educação Ambiental, Desenvolvimento, Desenvolvimento Local.

\footnotetext{
${ }^{1}$ Mestre do Programa de Pós-Graduação em Gestão de Recursos Naturais e Desenvolvimento Local na Amazônia (PPGEDAM/NUMA). E-mail: elitonaraujo@gmail.com

2 Docente do Programa de Pós-Graduação em Gestão de Recursos Naturais e Desenvolvimento Local na Amazônia (PPGEDAM/NUMA). E-mail: marilenals@ufpa.br
} 


\section{Introdução}

Ao longo da história, o conceito de desenvolvimento que tem se construído demonstra uma grande influência do meio de produção capitalista. Esse modelo de desenvolvimento consiste na concentração de capital nas mãos de poucos, gerando desigualdades na outra parte da população que não tem acesso a esse recurso. Além do mais, para sustentar os seus padrões de consumo, esse modelo ver o meio ambiente apenas como fonte de matériaprima, não estando preocupado com a problemática gerada pela extração em larga escala de recursos naturais.

O Desenvolvimento local surge como um contraponto a concepção de desenvolvimento centrada no crescimento econômico no progresso material. Na perspectiva do desenvolvimento local, ele surge de formar endógena, isto é, nascendo no seio do local e para o local, do homem para o homem, sendo este construtor do seu próprio desenvolvimento.

Nesta perspectiva, este artigo, objetiva apresenta uma possível articulação entre o desenvolvimento sustentável e a Educação Ambiental, sendo essa última, um importante instrumento para 0 alcance de tal desenvolvimento.

A primeira seção deste artigo, intitulada: Considerações sobre modelos de desenvolvimento, objetiva apresentar uma discussão teórica a respeito do conceito de desenvolvimento local, por meio de uma revisão bibliográfica, buscando explorar o posicionamento dos autores que se ocupam de pesquisar sobre essa temática.

$\mathrm{Na}$ segunda seção apresenta-se um breve histórico da Educação Ambiental em nível internacional e no Brasil. $\mathrm{Na}$ terceira seção discute-se o papel que a Educação Ambiental pode desempenhar enquanto instrumento para o desenvolvimento local, buscando aproximações entre os dois conceitos e uma possível articulação em prol do desenvolvimento, que priorize a participação dos atores locais na construção de seu próprio desenvolvimento e sobre tudo no atendimento de suas necessidades essenciais. Na última seção tecemos nossas considerações finais a respeito do estudo realizado.

\section{Considerações sobre modelos de desenvolvimento}

O desenvolvimento, como qualquer outro conceito, vem ao longo dos anos sofrendo modificações a partir da interpretação de pesquisadores que se ocupam deste tema de pesquisa. De acordo com Vasconcellos Sobrinho (2013, p. 14) este tema "somente se tornou um conceito em evidência nos últimos 60 anos, mais precisamente após o fim da segunda guerra mundial". Andion (2003, p. 1035), afirma que 
o termo desenvolvimento é interpretado como sinônimo de promoção de crescimento, progresso e aumento de riqueza, caracterizando o estágio econômico, social e político de uma dada comunidade com altos índices de rendimento dos fatores de produção (capital, trabalho e recursos naturais).

Battassini e Costa (2017, p. 03) corroboram com a concepção definida por esse autor e ainda acrescentam que esse conceito relacionado apenas com o progresso e o crescimento econômico é criticado por sua superficialidade. Ao longo dos anos, essa forma de pensar o desenvolvimento mostrou-se contraditória, visto que ao invés de gerar de fato o desenvolvimento acabou por estabelecer uma outra categoria denominada de subdesenvolvimento. Assim, Vasconcellos Sobrinho (2013, p. 14), afirma que

O que a história tem nos mostrado é que, infelizmente, as lógicas de desenvolvimento existentes até hoje no mundo contemporâneo tem trazido como antítese o subdesenvolvimento e/ou desenvolvimento para trás (retrocesso ou extinção) de algumas sociedades. Esta percepção se dá em função da forma empreendida pela lógica produtiva do sistema capitalista atual que, entretanto, ainda que timidamente, tem se modificado.

Essa proposta de desenvolvimento centra-se no acúmulo de capital sem levar em consideração o ser humano, e principalmente o meio ambiente, isto é, extraindo os recursos naturais sem preocupar-se com o seu esgotamento. $O$ objetivo desse modelo é o crescimento econômico e a concentração de renda nas mãos de poucos, gerando desigualdades sociais. A sociedade tem tratado os recursos naturais como fonte de matéria-prima e o meio ambiente como depósito dos resíduos, provocando agressões ao meio natural (BIGLIARD; CRUZ, 2017). A respeito do modelo capitalista, Guimarães (1995) afirma que

A dominação faz parte da lógica desse modelo de sociedade moderna e é esse modelo que apresenta como caminho o crescimento econômico baseado na extração ilimitada de recursos naturais, renováveis ou não, na acumulação contínua de capitais, na produção ampliada de bens, sem considerar as interações entre essas intervenções e o ambiente em que se realizam. E ainda, pela questão da dominação, apenas uma pequena parcela da população planetária usufrui dos benefícios desse sistema (GUIMARÃES, 1995, p. 13). 
Por meio desse modelo econômico acentuam-se as desigualdades sociais, pois apenas uma pequena parcela da população é beneficiada, gerando, conforme sustentado por Leroy e Pacheco (2011) além de guerra e miséria, um "desmonte sistemático das instâncias públicas de regulação (normas e legislação, justiça, serviços públicos, monopólio da força e planejamento público), nacionais e internacionais" (p. 33).

Como se há de verificar a crise que a sociedade está vivenciando nos dias atuais, além do forte apelo ambiental é também social. Guimarães (1995) afirma que a partir dessa forma de pensar o desenvolvimento passou a existir

uma sociedade consumista de recursos, capitais e bens. $\mathrm{O}$ consumismo intenso valoriza a acumulação material, a competição exacerbada, o individualismo egoísta vende uma ilusão alienante de crença na viabilidade desse modelo, que jamais poderia ser alcançado pelo conjunto da população planetária ou até mesmo pela grande maioria das nações existentes. Não há como se pretender que, dentro dessa estrutura, todas as nações atinjam o mesmo nível de desenvolvimento e o mesmo padrão de consumo dos atuais países desenvolvidos, sem que isso não resultasse em graves consequências ambientais (GUIMARÃES, 1995, p. 13).

Nesta linha de análise, está posta a necessidade do rompimento com esse padrão de consumo, o qual preza pela concentração da riqueza nas mãos de poucos, escravizando os menos favorecidos e também o meio ambiente, gerando graves problemas de ordem social e ambiental. Romper com essa forma de pensar o desenvolvimento, consiste na busca de uma nova forma de pensar a sociedade, norteada pela "conquista da cidadania, por padrões éticos pautados pela cooperação, solidariedade, respeito à diversidade e busca do bem comum para as gerações presentes e futuras" (BIGLARD; CRUZ, 2017, p. 128), isto é, "a atual tendência em se pensar e planejar o desenvolvimento é dotá-lo de um caráter mais humano, no sentido de considerar o homem simultaneamente como sujeito e beneficiário" (MARTINS, 2002, p. 51).

Neste contexto, surge uma nova alternativa de pensar 0 desenvolvimento, entendendo-o a partir do local, isto é, de acordo com Martins (2002), como "um produto da iniciativa compartilhada, da inovação e do empreendedorismo comunitário" (p.51). Surge, o conceito de desenvolvimento local, o qual vem contrapor a concepção de desenvolvimento centrada nos moldes mercadológicos. No desenvolvimento local, as ações estão centradas no homem, como construtor do seu próprio desenvolvimento, pessoal e comunitário.

Milani (2004) compreende o desenvolvimento local como 
o conjunto de atividades culturais, econômicas, políticas e sociais - vistas sob a ótica intersetorial e trans-escalar - que participam de um projeto de transformação consciente da realidade local. Neste projeto de transformação social, há significativo grau de interdependência entre os diversos segmentos que compõem a sociedade (âmbito político, legal, educacional, econômico, ambiental, tecnológico e cultural) e os agentes presentes em diferentes escalas econômicas e políticas (do local ao global). (p. 96).

É possível perceber a amplitude desse conceito, o qual envolve ações culturais, econômicas, políticas e sociais. Pode-se perceber que esse desenvolvimento não está centrado apenas no aspecto econômico, mas envolve também uma mudança cultural. Essas mudanças tendem a gerar um conflito, principalmente na definição das ações para o desenvolvimento, visto que cada ator do desenvolvimento possui seus interesses pessoais e comunitários. Desta forma, mesmo o desenvolvimento local, sendo uma alternativa que contrapõe o modelo mercadológico de desenvolvimento, o mesmo também possui dificuldades e conflitos a serem superados.

Nesta linha de análise, Campanhola e Silva (2000) ressaltam que o consenso dos atores locais em torno dos interesses comuns, ainda é considerando um dos maiores desafios na implantação de um processo de desenvolvimento local, isto é, de acordo com os autores "não há regras ou modelos predeterminados para a definição consensual dos objetivos e metas que conduzam ao desenvolvimento local' (p. 30).

De acordo com Buarque (1999, p. 09), o desenvolvimento local é considerado como "um processo endógeno registrado em pequenas unidades territoriais e agrupamentos humanos capaz de promover o dinamismo econômico e a melhoria da qualidade de vida da população".

O Desenvolvimento local além da dimensão econômica está atrelado a outras dimensões: ecológicas, culturais, sociais, econômicas, institucionais e políticas. Vale ressaltar que o conflito não está desatrelado desse conceito, considerando que os atores locais do desenvolvimento possuem interesses pessoais e comunitários. Independente disso, o mesmo apresenta-se como uma forma de promover a cidadania, com o enfoque no bem-estar do ser humano, de forma coletiva.

\section{Educação Ambiental em nível internacional e no brasil}

A Educação Ambiental tem seus primeiros passos a partir da realização da Conferência das Nações Unidas sobre o Ambiente Humano, realizada em Estocolmo, na Suécia, no período de 05 a 16 de junho de 1972. A partir da compreensão de que o ser humano é ao mesmo tempo obra e construtor do meio ambiente que o cerca, e que a aceleração da tecnologia o concedeu 
poderes de transformar o ambiente numa escala sem precedentes, nações do mundo inteiro reuniram-se para discutir essa problemática.

Pelo fato da proteção do meio ambiente já naqueles dias ser uma questão fundamental que afeta o bem-estar e o desenvolvimento econômico de todos os povos do planeta, os países reunidos na Conferência, assinaram um documento conhecido por Carta de Estocolmo, na qual foram definidos 26 princípios que passaram a nortear as ações governamentais dos países signatários. Dentre esses princípios, a educação foi recomendada como ferramenta fundamental para contribuir na formação de condutas que responsabilize os indivíduos para a proteção e melhoramento do meio ambiente.

Mais tarde, já em 1977, a Organização das Nações Unidas promoveu em Tbilisi, na Geórgia, a Conferência Intergovernamental sobre Educação Ambiental, que ficou popularmente conhecida por conferência de Tbilisi. Este evento passou a ser considerando o marco conceitual da Educação Ambiental. Nessa Conferência também foram definidos princípios e recomendações aos países participantes, incumbindo-os dentre outros compromissos, o de elaborar as diretrizes nacional de Educação Ambiental, respeitando a particularidade de cada nação.

Em nível Nacional a Educação Ambiental apesar de já ser tratada de maneira tímida na Política Nacional de Meio Ambiente, instituída pela Lei Federal no 6938/1981 e na Constituição Federal de 1988, teve seu marco principal com a sanção da Lei Federal o 9.795, de 27 de abril de 1999 que instituiu a Política Nacional de Educação Ambiental, tendo sido regulamentada pelo Decreto ํㅜ 4.281, de 25 de junho de 2002.

\section{A Educação Ambiental como instrumento para o desenvolvimento local e superação da pobreza}

A Educação Ambiental entendida como um processo pelo qual a coletividade constrói valores sociais, conhecimentos e atitudes voltadas para a conservação do Meio Ambiente, conforme preceituado pela Política Nacional de Educação Ambiental (PNEA), instituída através da Lei Federal $\mathrm{n}^{\circ}$ 9.795/1999, tem papel fundamental na construção de uma sociedade que busque desenvolver-se a partir das suas potencialidades locais.

Nesta linha de análise, Reigota (2012, p. 13) aponta que a Educação Ambiental como educação política tem compromisso com a ampliação da cidadania e de outros princípios, dentre eles: liberdade e autonomia, além do direito e dever de buscar soluções que viabilizem a convivência entre todos.

É preciso compreender que a Educação Ambiental não está somente relacionada à conservação dos recursos naturais, mas também com os problemas ambientais que o consumismo e outras questões relacionadas ao 
desenvolvimento causam na sociedade, entre eles: a pobreza e as desigualdades sociais. Neste sentido, Silva (2008) acredita que

Por Educação Ambiental deve ser entendida a dimensão da educação geral preocupada com a continuidade da vida no planeta, preocupada ainda com a construção de relações mais solidárias entre as pessoas e destas com a natureza exterior e interior, que the constitui enquanto seres relacionais. Nesse sentido, não há nenhuma novidade na proposição teórica da Educação Ambiental, na medida em que essa integra a educação geral, concebida como educação para a formação integral dos sujeitos humanos (SILVA, 2008, p. 29).

Há de se verificar que, além das preocupações relacionadas à conservação da natureza, a Educação Ambiental de forma crítica deve contribuir para a construção de relações sociais que estejam pautadas nos princípios da igualdade e fraternidade.

A Educação Ambiental representa um importante instrumento no enfrentamento da crise ambiental causada pelos padrões impostos pelo modelo de produção capitalista. Em se tratando de desenvolvimento, ela também tem um papel de destaque no combate ao desenvolvimento excludente e desigual centrado apenas na concentração de capital. A EA no ponto de vista da transformação traz consigo um olhar para a cidadania, contribuindo para a consolidação de sujeitos críticos de sua realidade.

Nessa perspectiva, Jacobi (1998, p. 12) afirma que

Quando nos referimos à EA, situamo-la num contexto mais amplo, o da educação para a cidadania, configurando-se como elemento determinante para a consolidação de sujeitos cidadãos. O desafio do fortalecimento da cidadania para a população como um todo, e não para um grupo restrito, concretiza-se a partir da possibilidade de cada pessoa ser portadora de direitos e deveres, e por conta disso, converter-se em ator corresponsável da defesa da qualidade de vida.

Um dos objetivos do desenvolvimento local é tornar o indivíduo como dinamizador de sua realidade local, construindo melhores condições de vida no aspecto individual e da coletividade. Neste sentido, é fundamental que cada cidadão esteja ciente do seu papel, bem como dos direitos e deveres que deve exercer. A Educação Ambiental numa perspectiva transformadora ${ }^{3}$ pode

\footnotetext{
${ }^{3}$ É aquela que possui um conteúdo emancipatório, em que a dialética entre forma e conteúdo se realiza de tal maneira que as alterações da atividade humana, vinculadas ao fazer educativo, impliquem
} 
contribuir para o desenvolvimento local, pois como visto no seu conceito, se faz necessário mudanças de hábito cultural e principalmente político, estando ciente que estes são pré-requisitos indispensáveis para a mudança da realidade comunitária. Nessa perspectiva, Loureiro (2009, p. 32) afirma que

A ação emancipatória é o meio reflexivo, crítico e autocrítico contínuo, pelo qual podemos romper com a barbárie do padrão vigente de sociedade e de civilização, em um processo que parte pelo sujeito, estabelecendo experiências formativas, escolares ou não, em que a reflexão problematizadora da totalidade, apoiada numa ação consciente e política, propicia a construção de sua dinâmica.

Retomando o conceito de desenvolvimento local, ressaltando que esse nasce no seio do local, de forma endógena ${ }^{4}$, isto é, de dentro para fora o autor ressalta que a Educação Ambiental, a partir do viés emancipatório pode proporcionar aos indivíduos experiências que possuam um caráter problematizador da sua realidade, estando assentado numa ação política.

Os autores Pinto e Lima (2004) acreditam que

Educação Ambiental é vista como um instrumento eficiente na potencialização do desenvolvimento local sustentável, considerando que a sua prática induz à mudança de hábitos, atitudes, valores, comportamentos e conceitos. Leva também a comunidade a momentos de reflexão sobre a realidade resignificando às práticas sociais, delineando assim uma nova visão dessa realidade que passa a ser transformada a partir de atitudes conscientes das pessoas.

A Educação Ambiental não é a única forma de se promover o desenvolvimento local, mas é um instrumento importante, levando em consideração que esta envolve a mudança de hábitos e nessa perspectiva de desenvolvimento, a mudança de hábitos e atitudes é primordial. Além do mais, é importante ressaltar, que esse processo de Educação Ambiental pode emergir a partir da escola como espaço de produção e difusão de conhecimento, mas não só dela, e sim de outras estruturas organizacionais da comunidade.

mudanças individuais e coletivas, locais e globais, estruturais e conjunturais, econômicas e culturais. Loureiro (2009, p. 89)

4 Buarque (1999, p. 09), entende desenvolvimento local como "um processo endógeno registrado em pequenas unidades territoriais e agrupamentos humanos capaz de promover o dinamismo econômico e a melhoria da qualidade de vida da população. Representa uma singular transformação nas bases econômicas e na organização social em nível local, resultante da mobilização das energias da sociedade, explorando as suas capacidades e potencialidades específicas".

Revbea, V. 14, № 3: 355-366, 2019. 
Nesta linha de análise, Pinto e Lima (2004) também asseveram que

Para que a Educação Ambiental contribua na potencialização do desenvolvimento local, é preciso que a trajetória do seu processo educativo não se resuma exclusivamente à escola, mas que esteja articulada com o cotidiano das pessoas. Deve estar voltada para uma rede de ações e relações estabelecidas por meio de um conjunto de práticas desenvolvidas por diversos atores sociais em diferentes atuações cujo resultado se concretiza na localidade.

De acordo com Battassani e Costa (2017, p. 14),

Para tornar a Educação Ambiental um instrumento de desenvolvimento local é necessário a formação de uma nova consciência através do conhecimento e da reflexão sobre a realidade ambiental e social. Está voltada para o desenvolvimento de atitudes e condutas que favoreçam o exercício da cidadania, a conservação do meio ambiente e a promoção da saúde e do bem-estar.

Mais uma vez visualiza-se como indispensável a inserção da Educação Ambiental no processo de desenvolvimento local, considerando que o processo de mudança por parte dos atores locais do desenvolvimento deve ser mediado para que estes possam discernir sobre o caminho que desejam seguir. Nesta perspectiva, Loureiro (2009, p. 91), afirma que: "Educação é emancipação, portanto, deve instrumentalizar e preparar o indivíduo para escolher livremente os melhores caminhos para a vida que se quer levar em sociedade e em comunhão com a/na natureza".

Battassani e Costa (2017, p.13) acreditam que

O processo de desenvolvimento local, como da Educação Ambiental, aparece como um caminho (que se faz ao caminhar) a ser seguido para se chegar à satisfação em qualidade de vida da coletividade, o qual permite perceber a importância do envolvimento de todos os setores da sociedade, considerando o trabalho integrador, assim como a sua autosustentabilidade. $O$ aproveitamento do potencial da comunidade local resgata e valoriza a sua cultura, fazendo com que as pessoas sintam-se responsáveis e envolvidas na busca das soluções dos problemas locais, promovendo mudanças no comportamento. 
Outra referência que ratifica a Educação Ambiental como um importante instrumento para a promoção do desenvolvimento local, é o tratado de Educação Ambiental para Sociedades Sustentáveis e Responsabilidade Global, aprovado durante a realização da Conferência Mundial Rio 92, de forma paralela no Fórum Global das Organizações Não-Governamentais. O tratado possui uma cadeia de princípios que objetivam nortear as ações de Educação Ambiental. No Quadro 1, apresentamos os que mais se relacionam com a intercessão entre Educação Ambiental e desenvolvimento local.

Quadro 1: Princípios do tratado de Educação Ambiental para Sociedades Sustentáveis e Responsabilidade Global relacionados ao Desenvolvimento Local.

\begin{tabular}{|c|l|}
\hline No & \multicolumn{1}{|c|}{ Princípio } \\
\hline 2 & $\begin{array}{l}\text { A Educação Ambiental deve ter como base o pensamento crítico e inovador, em } \\
\text { qualquer tempo ou lugar, em seu modo formal, não-formal e informal, } \\
\text { promovendo a transformação e a construção da sociedade. }\end{array}$ \\
\hline 4 & A Educação Ambiental não é neutra, mas ideológica. É um ato político. \\
\hline 5 & $\begin{array}{l}\text { A Educação Ambiental deve envolver uma perspectiva holística, enfocando a } \\
\text { relação entre o ser humano, a natureza e o universo de forma interdisciplinar. }\end{array}$ \\
\hline 8 & $\begin{array}{l}\text { A Educação Ambiental deve facilitar a cooperação mútua e eqüitativa nos } \\
\text { processos de decisão, em todos os níveis e etapas }\end{array}$ \\
\hline 10 & $\begin{array}{l}\text { A Educação Ambiental deve estimular e potencializar o poder das diversas } \\
\text { populações, promovendo oportunidades para as mudanças democráticas de base } \\
\text { que estimulem os setores populares da sociedade. Isto implica que as } \\
\text { comunidades devem retomar a condução de seus próprios destinos. }\end{array}$ \\
\hline 12 & $\begin{array}{l}\text { A Educação Ambiental deve ser planejada para capacitar as pessoas a } \\
\text { trabalharem conflitos de maneira justa e humana. }\end{array}$ \\
\hline 13 & $\begin{array}{l}\text { A Educação Ambiental deve promover a cooperação e o diálogo entre indivíduos } \\
\text { e instituições, com a finalidade de criar novos modos de vida, baseados em } \\
\text { atender às necessidades básicas de todos, sem distinções étnicas, físicas, de } \\
\text { gênero, idade, religião ou classe. }\end{array}$ \\
\hline
\end{tabular}

Fonte: Adaptado pelo autor, a partir de Tratado (2018).

É possível perceber que há uma articulação existente entre a Educação Ambiental e a promoção do desenvolvimento local que satisfaça as necessidades da coletividade local, preocupando-se também com a gestão dos recursos naturais. De acordo com Sorrentino, Trajber e Ferraro Junior (2005, p. 287), "a Educação Ambiental, em específico, ao educar para a cidadania, pode construir a possibilidade da ação política, no sentido de contribuir para formar uma coletividade que é responsável pelo mundo que habita". Assim, acreditase que a Educação Ambiental tem papel fundamental na construção de coletividades autônomas que possam promover ações que repercutam no desenvolvimento local, tanto no aspecto individual, como comunitário. 


\section{Considerações finais}

O desenvolvimento local entendido de forma endógena, que nasce no seio do local, possui além da dimensão econômica, outras dimensões que estão atreladas a essa forma de desenvolvimento, dentre elas as dimensões: cultual, ambiental e política. O processo de construção do desenvolvimento envolve prioritariamente a participação dos atores locais, como construtores de seu próprio caminho rumo à satisfação de suas necessidades. Essa proposta de desenvolvimento contrapõe o modelo centrado no modo de produção capitalista que visa apenas a concentração de capital, gerando desigualdades sociais e outras mazelas enfrentadas pela maior parte da população.

É preciso evidenciar que o desenvolvimento local não é uma receita pronta a ser aplicada em qualquer realidade. É necessário que seja realizado um processo de construção coletiva que relacione todas as demandas comunitárias. Esse processo também está sujeito a conflitos, considerando os interesses individuais dos atores locais do desenvolvimento.

A Educação Ambiental numa perspectiva emancipatória, assume papel fundamental na construção desse desenvolvimento local, levando em consideração, que a sua prática induz na mudança de hábitos e comportamentos dos indivíduos. Seja na Escola, por meio da Educação Formal, ou de caráter não formal em diversos grupos sociais existentes no local, ela se apresenta como um importante instrumento para o rompimento com a barbárie do padrão de sociedade e desenvolvimento que atualmente vigora.

\section{Referências}

ADION, C. Análise de redes e desenvolvimento local sustentável. RAP. v. 37, n. 5, p. 1033-1054, set./out., 2003.

BATTASSANI, P.S.A.; COSTA, R.B. Desenvolvimento Local e Educação Ambiental: Questões e Desafios. Disponível em: <http://www.cenedcursos. com.br/upload/ea dl.pdf>. Acesso em: 05 nov. 2018.

BIGLIARDI, R.V.; CRUZ, R.G. O papel da Educação Ambiental frente à crise civilizatória atual. Ambiente e Educação, Rio Grande, v. 12, n 01, p. 127-141, 2007.

BUARQUE, S.C. Metodologia de Planejamento do desenvolvimento local e municipal sustentável. Disponível em: <http://www.iica.org.br/docs/ publicacoes/publicacoesiica/sergiobuarque.pdf>. Acesso em: 10 nov. 2018.

CAMPANHOLA, C.; SILVA, J.G. Desenvolvimento Local e a Democratização dos espaços rurais. Cadernos de Ciência \& Tecnologia, Brasília, v.17, n.1, p.11-40, jan./abr. 2000.

GUIMARÃES, M. A dimensão ambiental na educação. 10. ed. Campinas, SP: Papirus, 1995 (Coleção Magistério: Formação e Trabalho Pedagógico). 
JACOBI, P. Educação Ambiental e Cidadania. In: CASCINO, F.; JACOBI, P.; OLIVEIRA, J.F. (orgs.) Educação, Meio Ambiente e Cidadania. São Paulo: SMA/CEAM, 1998.

LEROY, J.P.; PACHECO, T. Dilemas de uma educação em tempos de crise. In: LOUREIRO, C.F.B.; LEROY, J.P.; LAYRARGUES, P.P.; CASTRO, R.S. (orgs.).2. ed. São Paulo: Cortez, 2011.

LOUREIRO, C.F.B. Trajetória e Fundamentos da Educação Ambiental. 3. ed. São Paulo: Cortez, 2009.

MARTINS, S.R.O. Desenvolvimento Local: questões conceituais e metodológicas. Revista Internacional de Desenvolvimento Local, v. 3, n. 5, p. 51-59, set/2002.

MILANI, C. Teoria do Capital social e desenvolvimento local: Lições a partir da experiência de Pintadas (Bahia, Brasil). O\&S, v. 11, Edição Especial, p. 95-113, 2004.

PINTO, E.B.; LIMA, M.J.A. A contribuição da Educação Ambiental numa experiência de desenvolvimento local sustentável. Disponível em: $<$ http://www.fundaj.gov.br/images/stories/nesa/a contribuicao.pdf $>$. Acesso em: 03 nov. 2018.

REIGOTA, M. O que é Educação Ambiental. São Paulo: Brasiliense, 2012. (Coleção Primeiros Passos).

SILVA, M.L. Educação Ambiental e Cooperação Internacional na Amazônia. Belém: NUMA/UFPA, 2008.

SORRENTINO, M.; TRAJBER, R.; MENDONÇA, P.; FERRARO JUNIOR, L.A. A Educação Ambiental como política pública. Educação e Pesquisa, São Paulo, v. 31, n. 2, p. 285-299, maio/agosto, 2005.

TRATADO de Educação Ambiental para Sociedades Sustentáveis e Responsabilidade Global. Disponível em: $<$ http://portal.mec.gov.br/secad/arquivos/pdf/educacaoambiental/tratado.pdf >.

Acesso em: 16 set. 2019.

VASCONCELLOS SOBRINHO, M. Notas introdutórias sobre desenvolvimento e desenvolvimento territorial. In: MITSCHEIN, T.A.; ROCHA, G.M.; VASCONCELLOS SOBRINHO, M. Desenvolvimento local e o direito à cidade na floresta Amazônica. Belém: NUMA/UFPA, 2013 (Série Sociedade, Desenvolvimento Local e Meio Ambiente na Amazônia, nº 3). 